\title{
Study on the effect of toxicity under highly arsenic prone zone in Nadia district of West Bengal in India
}

Tanmoy Rana ${ }^{1}$, Samar Sarkar ${ }^{2}$, Tapan Kumar Mandal ${ }^{3}$, Subhasis Batabyal ${ }^{4}$, Bakul Kumar Datta ${ }^{1}$, Sumanta De ${ }^{1}$, Sourav Sikdar ${ }^{1}$

\author{
${ }^{1}$ Indian Veterinary Research Institute \\ ${ }^{2}$ Department of Veterinary Medicine, Ethics and Jurisprudence \\ ${ }^{3}$ Department of Veterinary Pharmacology and Toxicology \\ ${ }^{4}$ Department of Veterinary Biochemistry \\ West Bengal University of Animal and Fishery Sciences \\ Kolkata, West Bengal, India
}

\section{SUMMARY:}

The present study was carried out on the basis of status of arsenic in soil, drinking water and plants, blood, urine and faeces of animals at arsenic prone zone. Within the ambit with the environment, the examination of animals was taken into consideration. They were screened and categorised on the degree of As toxicity. For field works animals were randomly selected from arsenic prone zone. The external manifestation indicated a complex syndrome and characteristic signs such as increased heart rate and respiratory rate, red urine, congested mucous membrane, anorexia, absence of ruminal motility, diarrhoea with blood, polyuria and unusual weight loss. The haematobiochemical changes such as low Hb level, decreased level of TEC, TLC and increased level ALT, AST, BUN and creatinine. Increased level of arsenic in urine, blood and faeces than the value of control animals could be the confirmatory indication of arsenic toxicity.

\section{INTRODUCTION:}

Arsenic is a colourless, tasteless metalloid. It occurs in ground water in the form of arsenite, arsenate, methyl arsenic acid and dimethyl arsenic acid. Arsenite and arsenate compounds are highly toxic to human beings as well as animals (Singh et al., 2005).Large ruminants develop chronic arsenic toxicity after consuming large dose of poison as ruminal mass dilutes the arsenic concentration to a tolerable limit. If tolerance level crosses the critical limit animals show the symptoms like human beings. 
Ground water is one of the most important sources of drinking water and contamination of ground water with arsenic is one of the serious problems encountered in India. Soil contamination with arsenic occurs through the vehicle contaminated groundwater being used for irrigation. Arsenic contamination of plants occurs by irrigation with contaminated ground water.

The tolerance level of arsenic varies from animal from animals in age, sex, physiological status, nutritional status, route of exposure and biological availability (Sarder, 2004).

The arsenic concentrations in the water could affect human health through milk intake, since the allowable limit for water used to feed cattle is $0.05 \mathrm{mg} / \mathrm{L}$ (USEPA, 1973).

In view of the emergent affairs in the state, the present study was therefore undertaken to make a relationship on the soil-plant-water-animal system and to represent graphically to determine arsenic concentration considering the scattered economic condition particularly in the rural areas where about $80 \%$ of the population lives to prevent further losses and for economic emancipation of poor villagers to some extent.

The present study was conducted in graphical mode to analyze

1. To ascertain the degree of exposure to arsenic of selected animals of that area of study through intake of food contaminated by arsenic through irrigated arsenic contaminated groundwater and environment exposure.

2. To clarify the toxicity level of arsenic on animals resulting from exposure to arsenic through arsenic contaminated drinking water and plants.

3. To examine the clinical symptoms of arsenic poisoning.

4. To visualize the haematobiochemical changes of arsenic toxicity in animals. 


\section{MATERIALS AND METHODS:}

\section{Selection of area:}

The investigation was undertaken on clinical cases as well as on healthy animals in Nonaghata area of the Haringhata block of Nadia district of West Bengal in India.

\section{Collection of soil, water and Plants sample:}

The soil samples $(n=5)$ for analysis were collected from the grazing field of animals in Nonaghata mouza of the Haringhata block of Nadia district in West Bengal. The soil was processed by using standard formula described by (Jackson, 1967).

Water samples $(n=5)$ were preserved with $4 \mathrm{ml}$ concentrated hydrochloric acid ( $\mathrm{HCl})$ per litre and analyzed within 7 days of collection (Das et al., 2000).

The paddy plants $(n=5)$ consumed by the animals of the pasture land grown in the soil of the grazing areas of that affected area collected in two envelop containing sample no., area of collection and date for each sample and the samples were processed further as per the method described by AOAC (1975).

The processed soil(described by Jackson, 1967), drinking water and plants samples (described by Jackson, 1967) were used for the estimation of Arsenic with the help of Atomic Absorption Spectrophotometer (AAS) against standard solution of arsenic and values are expressed in terms of $\mu \mathrm{g} / \mathrm{gm}($ or ppm) or . $\mu \mathrm{g} / \mathrm{gml}(\mathrm{ppm})$. 

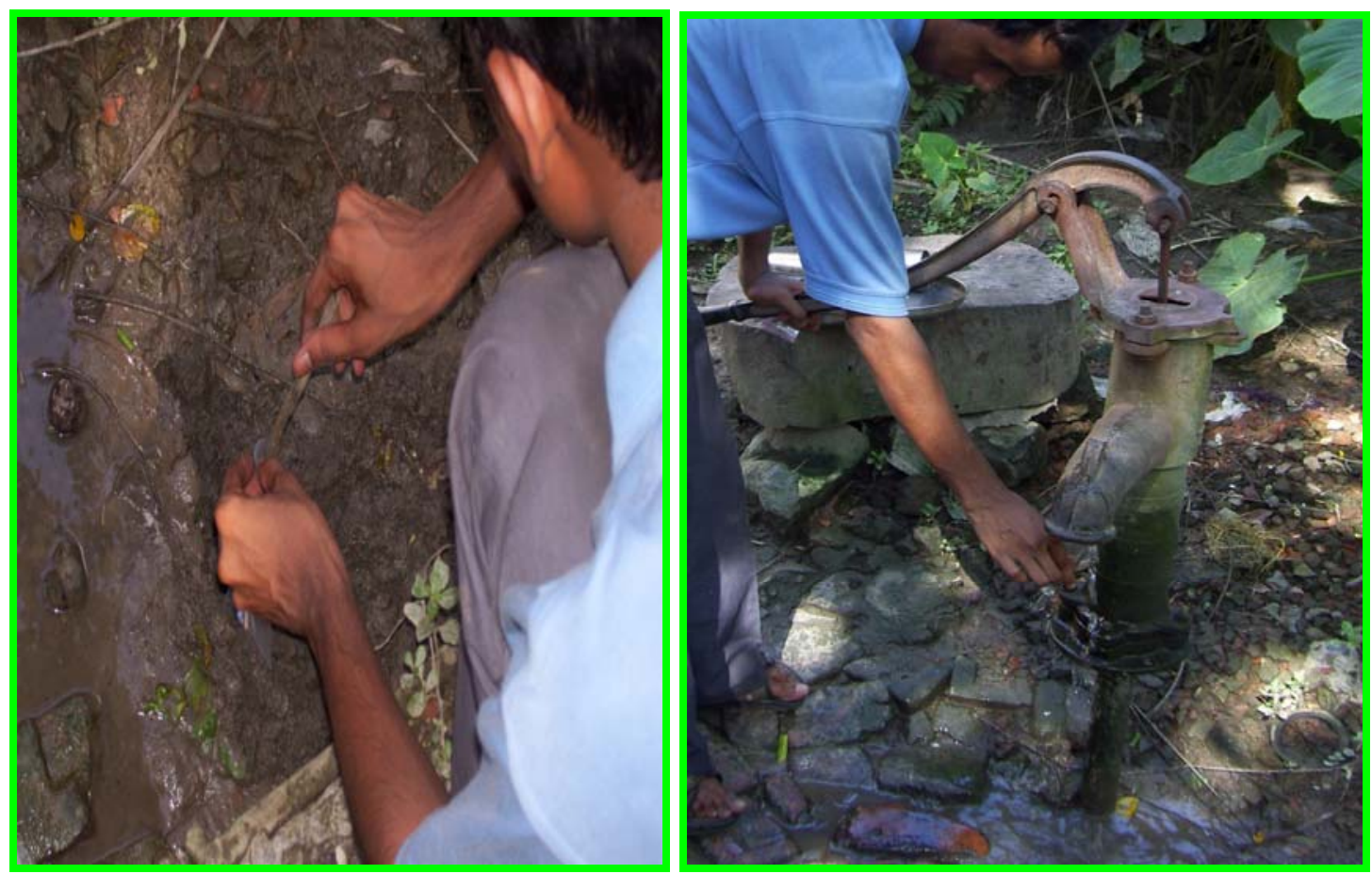

Fig.1 Collection of Soil and water sample from arsenic affected area

\section{Experimental Design:}

\section{Selection of arsenic affected and control animal:}

We selected arsenic affected cattle by observing the clinical signs which included weakness, dehydration, reddish urine, epilated hair, hyperpigmentation, hyperkeratosis, polyuria, polydipsia, anaemia and congested mucous membrane. They were categorized as Group (Gr). II. and healthy cattle from non affected zone was selected as Control group (Gr. I)

\section{Haematobiochemical Parameters:}

Heamatobiochemical parameters were estimated by standard methodology. As Haemoglobin ,Total Erythrocytic Count (TEC),Total leucocytic Count(TLC) described by Schalm et al.(1986).Estimation of Total Serum Protein, Blood Glucose Level, Aspertate Aminotransaminase (AST), Alanine amino Transaminase (ALT), Blood Urea Nitrogen (BUN) and Serum Creatinine were described by Kollar 
(1984), Hultman (1959), Reitman and Frankel (1957), Marsh (1965)and Toro and Ackermann (1975).

\section{Collection of blood, urine, faeces and milk samples:}

Blood, urine and faecal samples were collected from both arsenic affected of arsenic contaminated area and healthy animal of non affected zone.

Arsenic content in blood of control and experimental animals was estimated as per AAS method described by Sandal (1950) Arneza et al. (1977) \& Sarkar (1989).

Urine samples of animals were collected in prewashed and dried plastic bottles. The faecal samples were collected (10 gm) in polythene zipper bag and stored at $20^{\circ} \mathrm{C}$ until further analysis (Sarder, 2004).

Cow's milk was obtained during the cow's milking and 1-L was placed into a polyethylene bottle previously rinsed with $20 \%$ nitric acid in deionized water (Rosas et al., 1999).

The procesed aliquots were used for the estimation of arsenic in the urine and faeces (Sarder, 2004) and milk (Rosas et al., 1999) by AAS and values were expressed in terms of $\mu \mathrm{g} / \mathrm{ml}$ or $\mathrm{ppm}$ (for urine) and $\mu \mathrm{g} / \mathrm{gm}$ or ppm (for faeces) and $\mu \mathrm{g} / \mathrm{gm}$ or ppm (for milk). 

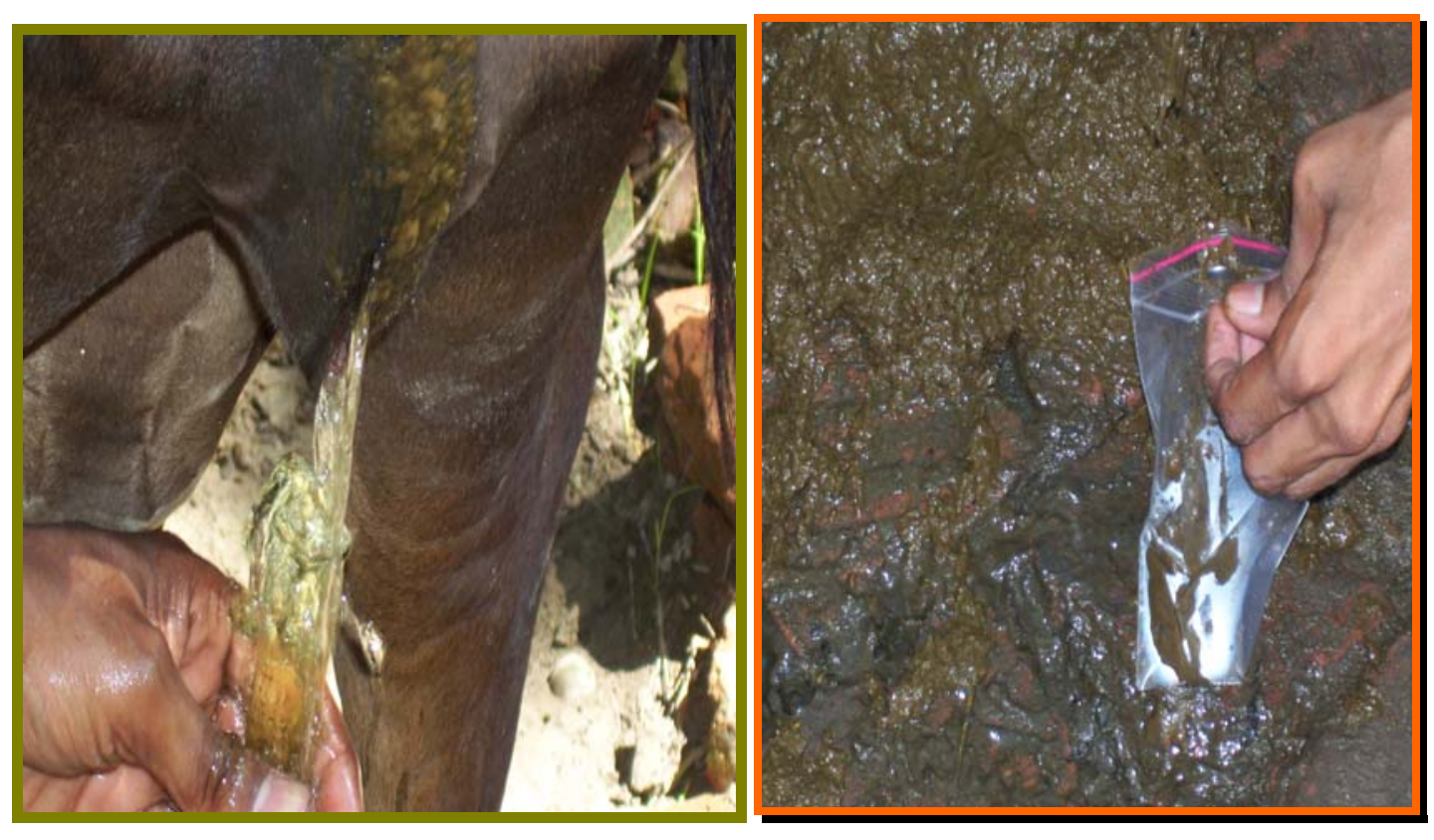

Fig.2 Collection of urine and faecal sample from cattle of arsenic affected area

\section{Ananlysis:}

A Perkin-Elmer Model 460 atomic absorption spectrophotometer equipped with MHS-10 Mercury/Hydride System and a HGA-2100 grafite furnace was used. A perkin-Elmer arsenic electrode less discharge lamp was used as a light source. Measurement was made with deuterium background correction. To determine total arsenic in soil, drinking water, plants and milk, $1 \mathrm{ml}$ of $10 \%$ potassium Iodide solution was added to $10 \mathrm{~mL}$ of sample or an aliquot diluted to $10 \mathrm{ml}$. After $60 \mathrm{~min}$, arsenic was determined by the hydride evolution method with sodium borohydride and theMHS10Mercury/Hydride System (Perkin-Elmer, 1979). Calibration was performed by preparing series of standards adding specific chemicals from the various matrices. The As (III) was measured by Graphite Furnace Atomic Absorption Spectrometry (GFAAS) by injecting $20 \mu \mathrm{L}$ of the MIBK phase into the graphite tube. The concentration of As $(\mathrm{V})$ in water samples was obtained by subtracting the values of As (III) from the total arsenic concentrations (Rosas et al.1999). 

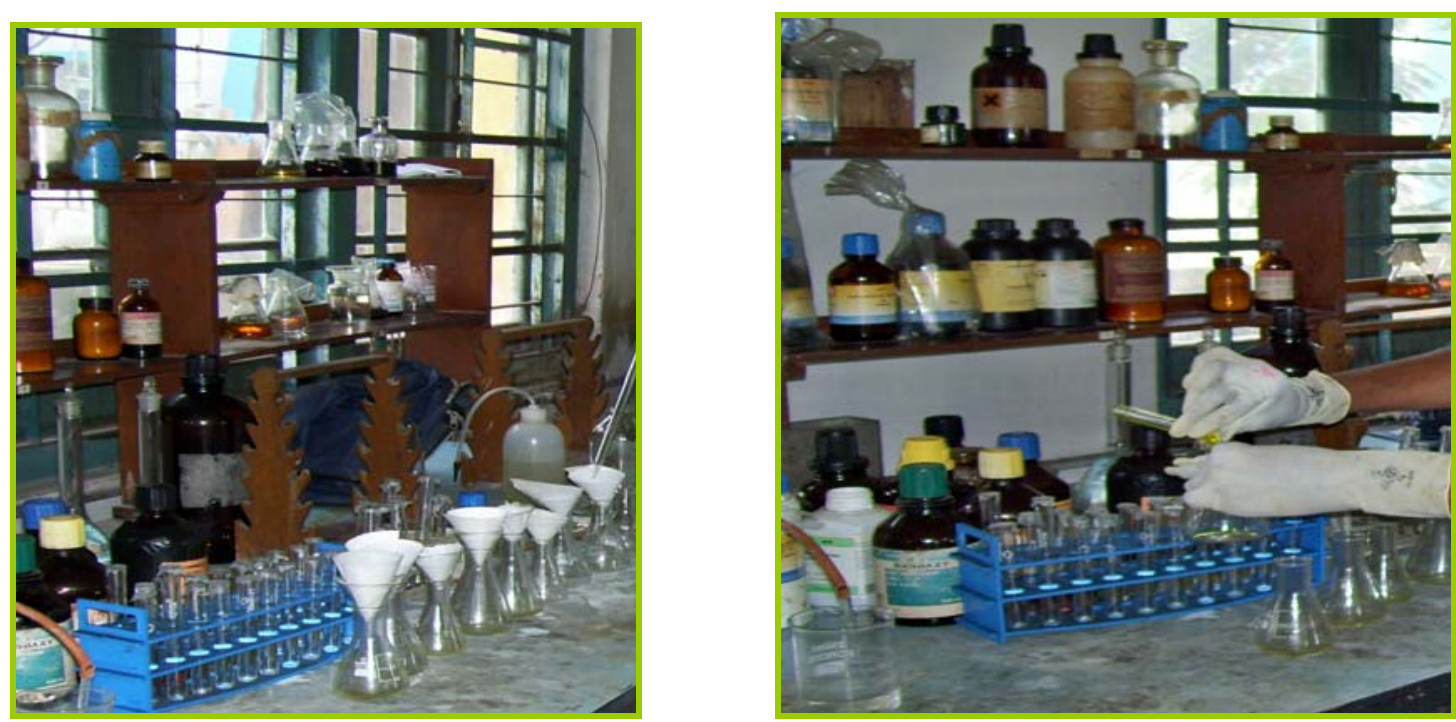

Fig3 Processing of samples for estimation of arsenic
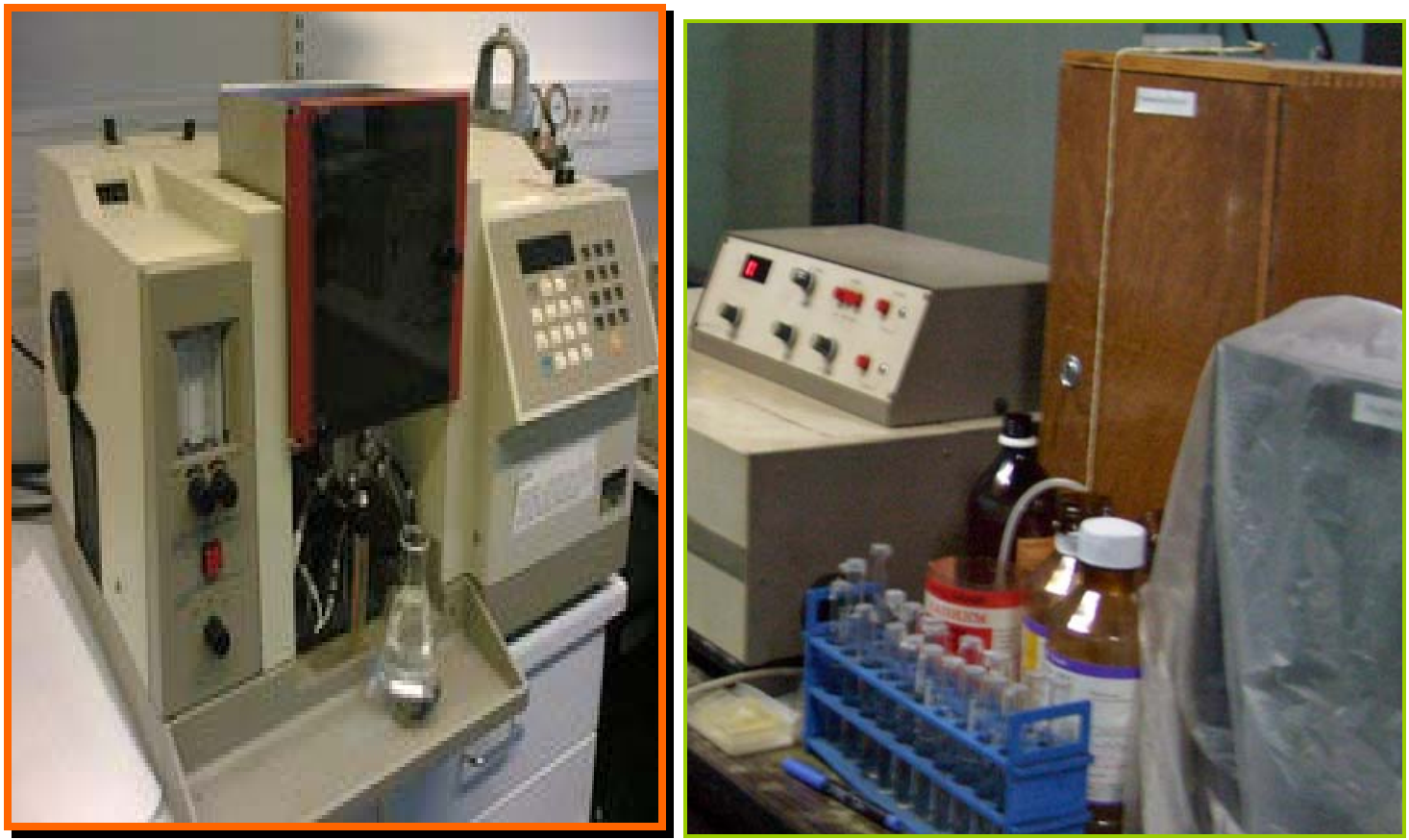

Fig. 4. Estimation of arsenic by atomic Absorption Spectrophotomete (AAS) and biochemical parameters by using Spectrophotometer (single beam). 


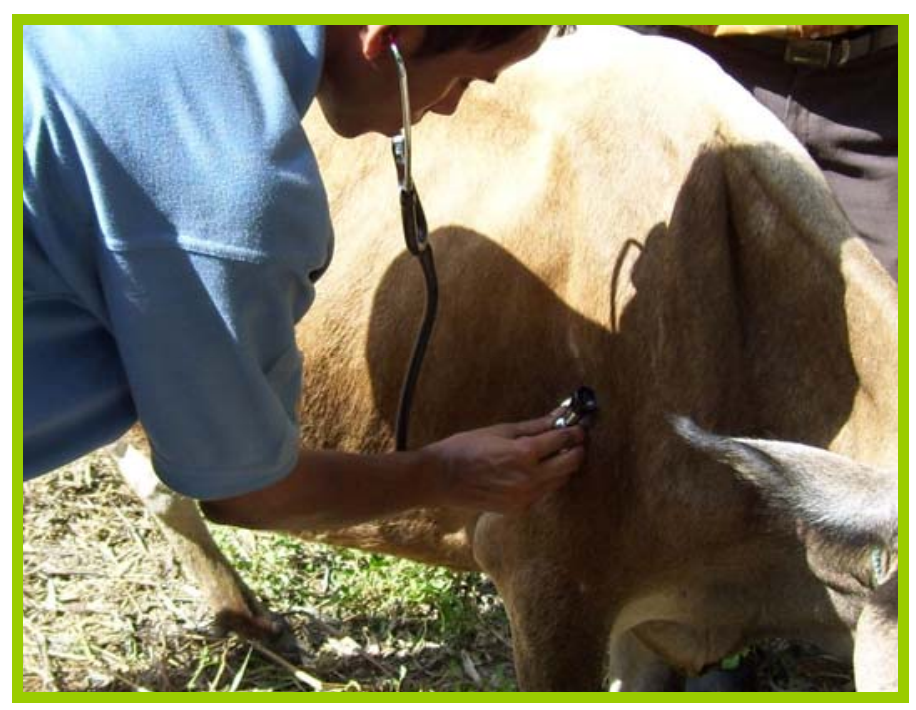

Fig. 5. Clinical examination of arsenic affected cattle

\section{RESULTS AND DISCUSSION:}

\section{Arsenic in soil samples:}

We have detected concentration of soil sample $(\mathrm{n}=5)$ of arsenic contaminated area. The graphical representation (fig. 6) showed that the concentrations of arsenic in that area were higher than the detectable limit of arsenic standard (10ppm). The results were corroborated with the reports of Pal et al. (2007) and Das et al.(2003).from the graph it was shown that the arsenic in soil is leached out and contaminates the irrigation water and the irrigated and contaminated water is the primary source for drinking. From the collection of 5 samples the concentration of arsenic of second sample was more than $14 \mathrm{ppm}$ that is dangerous whenever it is leached out. 


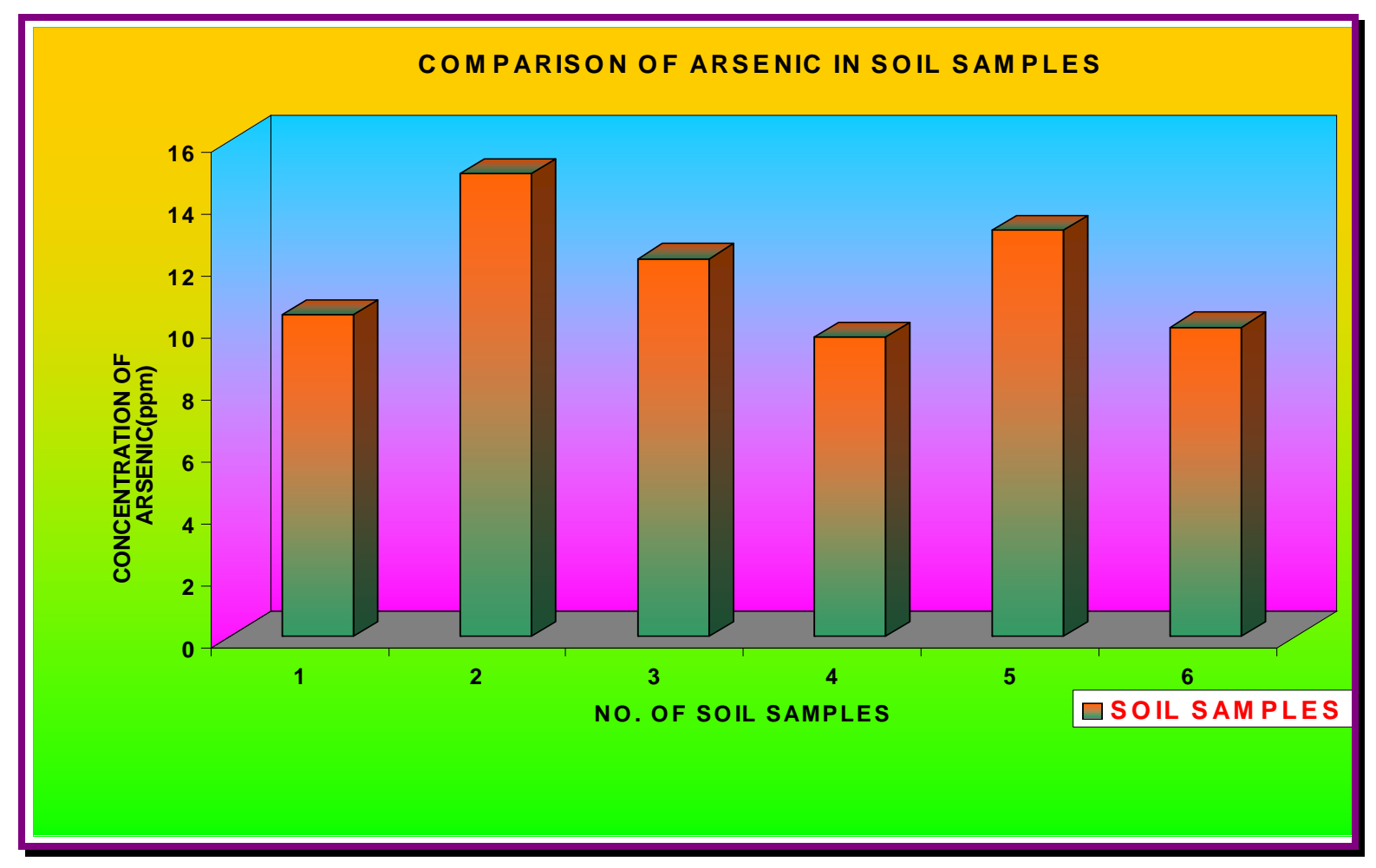

Fig.6 showed the comparison arsenic in soil samples with Standard (10ppm)

\section{Arsenic in water samples:}

The surface water is being contaminated because of the probable dislocation of contaminated groundwater due to the heavy rains in monsoon season (Pandey et al., 2002). We analyzed the water samples $(n=5)$ from shallow tube well water and the concentration of arsenic in drinking water is high than the permissible limit of 0.05ppm (Routh et al., 2003) .The graphical representation (fig.7) showed that the arsenic level in water of that area crosses the detectable limit and the animals were given the contaminated water. As a result slowly deposition of arsenic in tissue of animal causes G.I and Nervous disorders primarily and other associated complications are prevailed. 


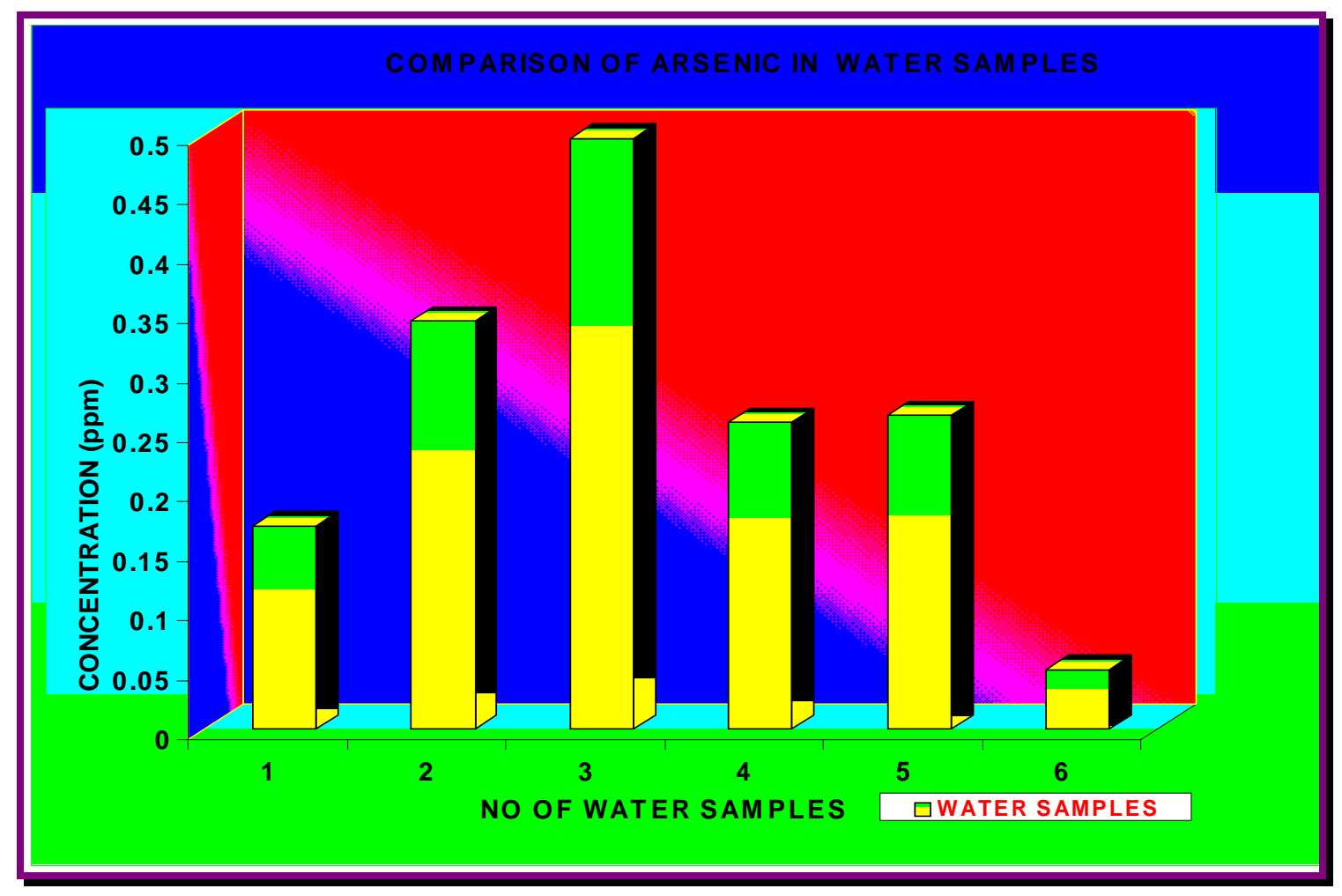

Fig.7 depicted comparison of arsenic in water samples with Standard (0.05 ppm) (WHO recommendation).

\section{Arsenic in plants:}

Paddy is the most important amongst the crops grown in India. Paddy grown on the soils adjacent to the contaminated water was the primary criteria for us and we wanted to justify how arsenic in plants hampers food chain circle. From the graph (fig.8) it was shown that arsenic in paddy plants $(n=5)$ was higher than the standards (0.005 ppm) (Korenovska, 2001). Arsenic accumulation in rice straw could be a direct threat for their health and also, indirectly, to human health, via presumably contaminated bovine meat and milk (Abedin et. al., 2002).The findings was corroborated with the reports of Das et al., 2003, Sanyal and Dhillion, 2005.

In this study, it is experimentally proved that shallow tube well water in the Nonaghata area is contaminated with arsenic and acts as the primary source of arsenic poisoning among the inhabitants and livestock. The results indicate that human populations as well as livestock populations are affected with arsenic from drinking of 
contaminated water for a long time. From that ground water source, top soils are also locally contaminated with arsenic leading to a significant accumulation of that plant.

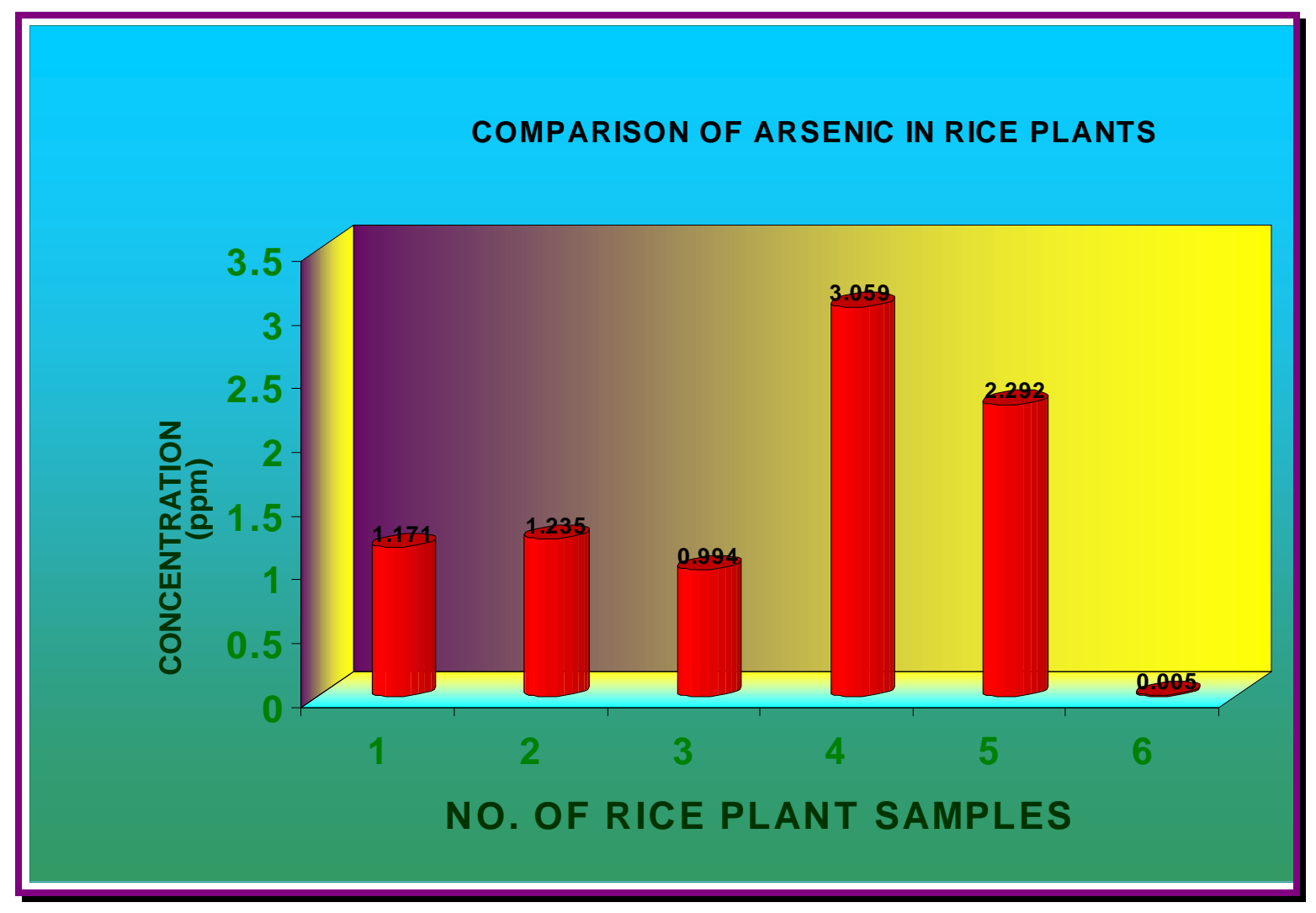

Fig.8 indicated comparison of arsenic in plants samples with Standard 0.005ppm

\section{Health Hazards:}

Clinical signs:

The arsenic affected animals showed diarrhea with blood, congested mucous membrane, haemoglobinuria, ruffled skin and hair, anorexia, dullness and spontaneous micturition. The most critical signs were hyperkeratosis, hyper pigmentation as human beings.these findings were corroborated with the reports of Biswas et al. (2000), Kent, 1998 and Blood et al., 2000. 


\section{Haematobiochemical Parameters:}

From the fig.(9) and fig (10) the graphical representation showed that $\mathrm{Hb} \%$, Total Erythrocytic Count (TEC), Total Leucocytic Count (TLC) and Total serum Protein(TSP) of affected cattle (Gr.II) were decreased than healthy cattle (Gr. I). As a result chronic arsenic toxicosis in animals cause anemia. These findings were in close similarity with the reports of Goodman and Gilman, 1990 and Kent, 1998. There is increased levels Blood Glucose Level (BGL), Aspertate Aminotransaminase(AST), Alanine aminotransaminase (ALT), Blood Urea Nitrogen(BUN) and creatinine where as AST enzyme elevated showed the drastic evidence for liver toxicity in ruminants. The findings were corroborated with the reports of Ianchev, 2001, Fusari and Ubaldi, 2000.

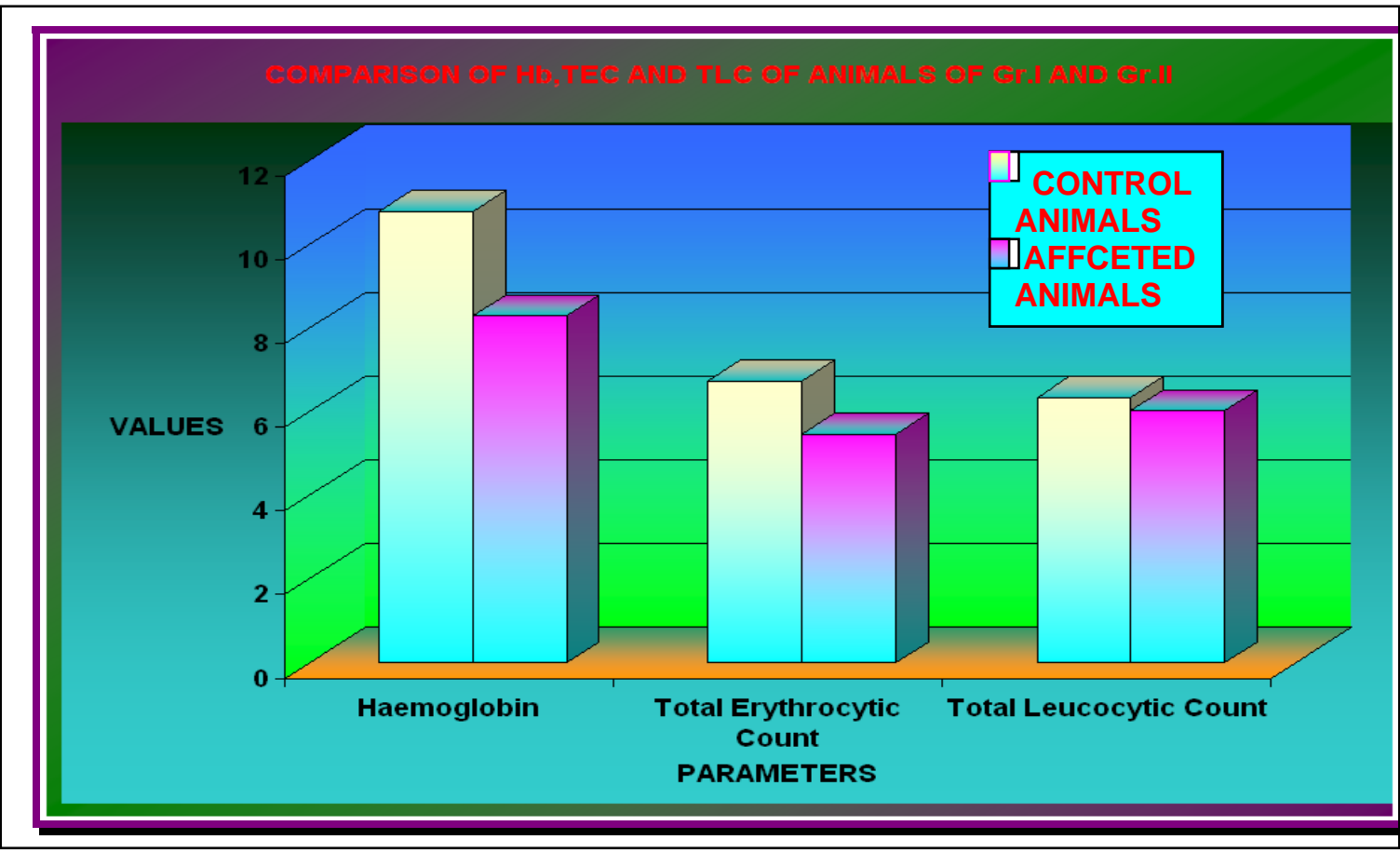

Fig. 9 showed comparison of Hb, TEC and TLC of animals of control (Gr.I) and affected (Gr.II.) animals. 


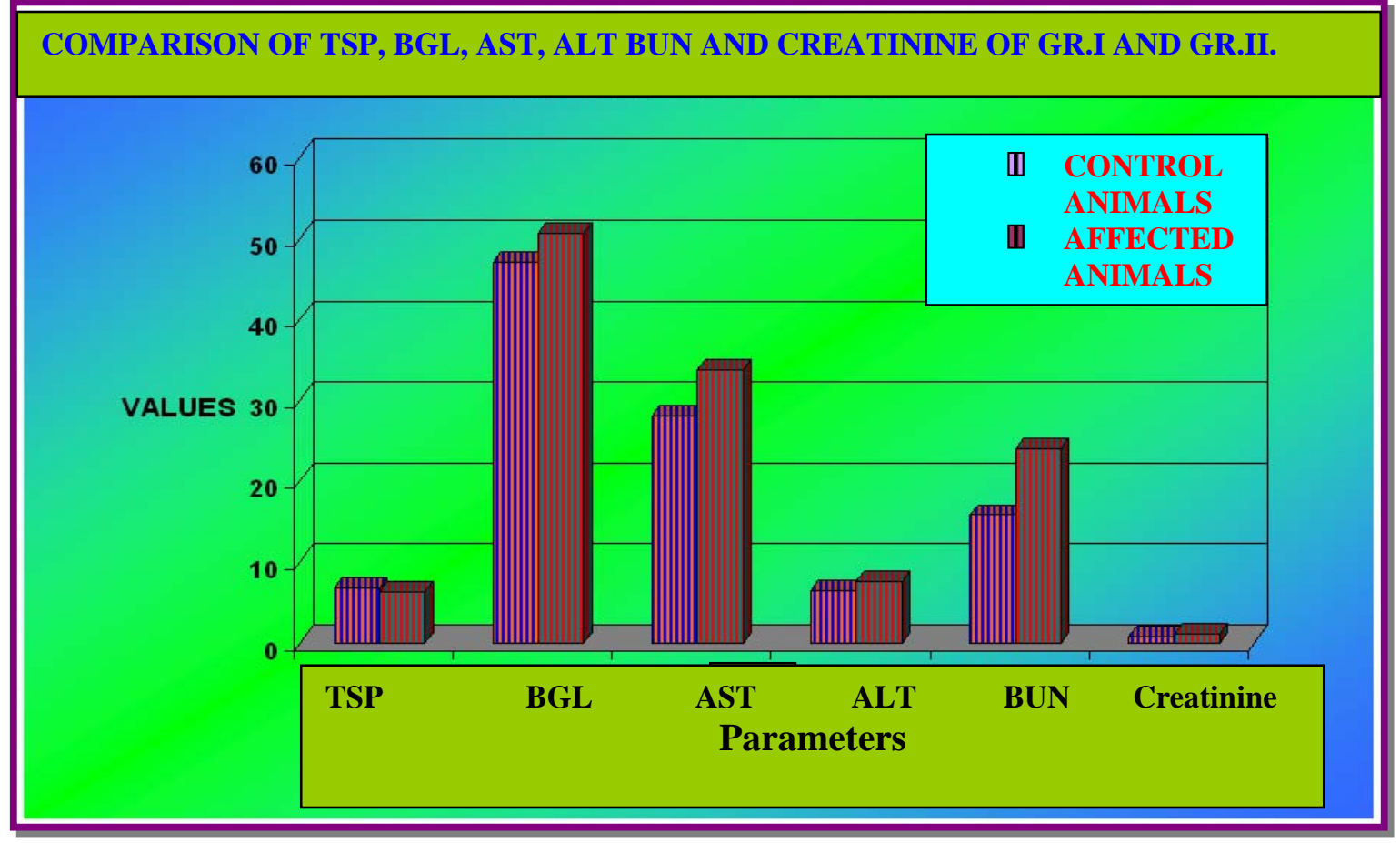

Fig. 10 depicted comparison of TSP, BGL and AST, ALT, BUN and Creatinine of control (Gr.I) and affected (Gr.II) animals.

\section{Blood, Urine and Faeces:}

As the area is highly arsenic contaminated zone so the levels of arsenic in blood, urine, faeces and milk samples (fig. 11) were higher than the healthy cattle of non affected zone. These findings were in close similarity with the reports of Selby et al.1974, Buck et al., 1976 and Rosiles, 1977.The concentration of arsenic in faeces in affected animals was higher than the concentration of arsenic in urine. The figure represented that the excretion of arsenic through faeces was more than the arsenic through urine. As a result, arsenic hampers the liver and kidney.

The milk is the secretary product of animals and the concentration of arsenic was higher than the milk of healthy cattle of non affected zone. The graphical representation was corroborated with the reports of Sahli, 1982, Rosas et al., 1999. The 
milk has its public health importance and contaminated milk (level of arsenic is higher) hampered food web as it is dangerous for human consumption.

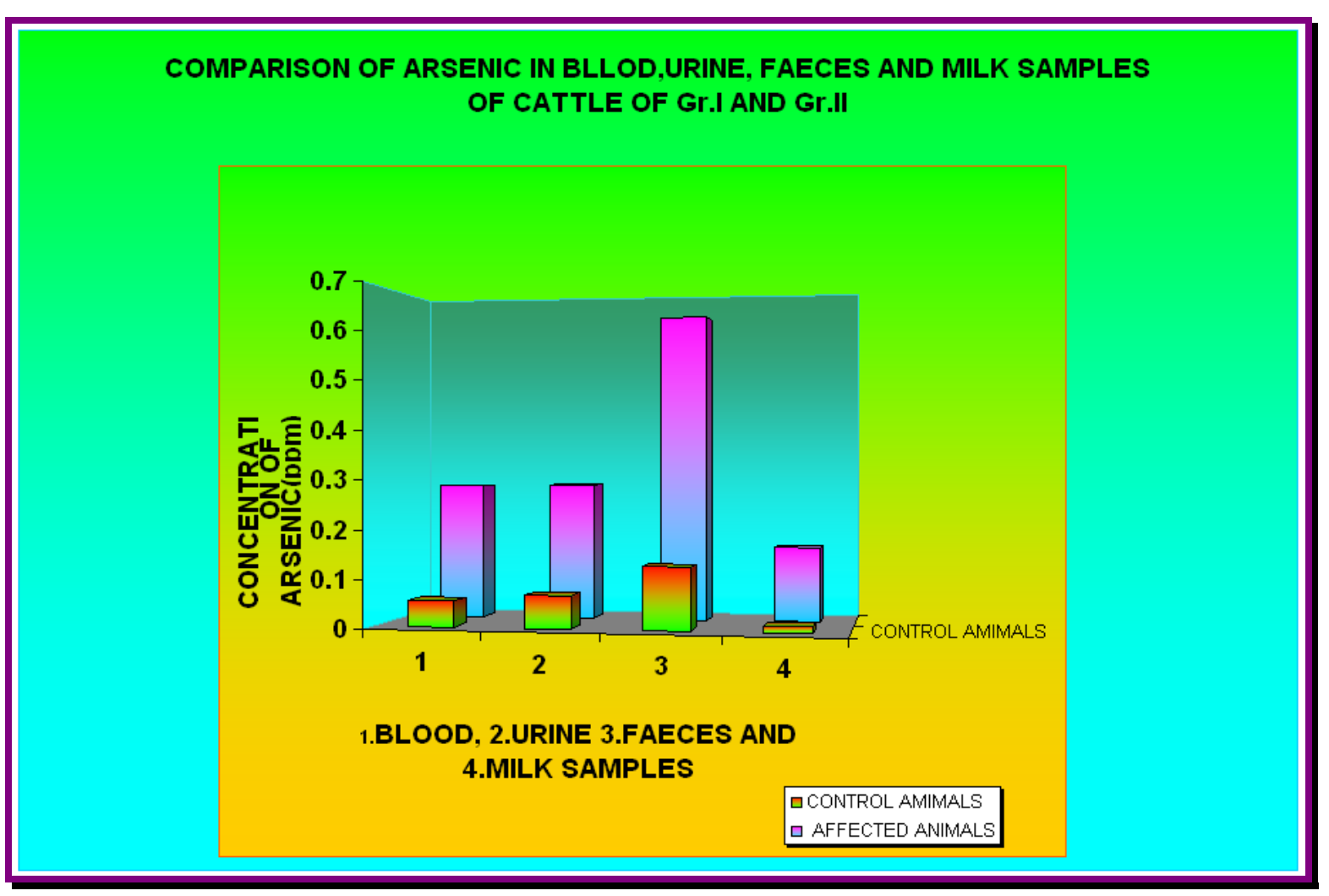

Fig 11 showed comparison of arsenic in blood, urine, faeces and milk of control (Gr.I) and affected (Gr.II) animals.

\section{CONCLUSIONS:}

From the study it can be concluded that the shallow ground water and surface water is contaminated with arsenic. Plants accumulate arsenic through the localised contaminated groundwater sources. Sustainable drinking of water containing As more than permissible limit in cattle. The consequences therefore are to make arsenic exposure in food chain and to reflect the translocation of biodiversity equilibrium.

The disorders of arsenic toxicity were characterised by marked clinical signs such as increased heart rate and respiratory rate, red urine, congested mucous 
membrane, anorexia, anoestrous, absence of ruminal motility, diarrhoea with blood and polyuria and unusual weight loss and epilated hair and skin.

Increased levels of arsenic in urine, blood and faeces than the value of control animals could be the confirmation of indication of arsenic toxicity in animals in that contaminated area and also hampers food chain system in the environment.

\section{REFERENCES:}

A.O.A.C. (1975). Official method of analysis. 12th Ed. Association of official agricultural chemicals, Washington, D.C.

Abedin,M.G., Howells,j.C., Meharg, A.A.(2002): Plant Soil, 240, 311-319.

Arenza, J.S., Hathi, S.D., Singh, B. and Verna, P.N. (1977). Status of some micro minerals in neonatal buffalo calves and their mothers. Ind. J. Dairy. Sci., 30: 255

Biswas, U., Sarkar, S., Bhowmik, M.K., Samanta, S.K. and Biswas, S. (2000). Chronic toxicity of arsenic in goats: clinicobiochemical changes, pathomorphology and tissue residues. Small Rumin Res.38 (3),229-235.

Buck, W.B., Osweiler, G.D. and Van Gelder, G.A. (1976). Clinical and Diagnostic Veterinary Toxicology. 2nd Ed. Kendall Hunt, Dubuque.

Das, I., Ghosh, K. and Sanyal, S.K. (2003). A report on Phytoremediation: a potential option to mitigate arsenic contamination in soil-water-plant system. Bidhan Chandra Krishi Viswavidyalaya, Nadia, West Bengal.

Goodman Gilman, A., Rail, T.W., Nies, A.S., and Taylor, P. (1990). Goodman and Gilman's The Pharmacological Basis of Therapeutics. 8th Ed. Pergamon 
Press. New York, Oxford, Beijing, Frankfurt, Sao Paulo, Sydney, Tokyo and Torento, pp.1602-1605.

Hultman, E (1959). Rapid specific method for determination of aldosaccharides in body fluid, Nature, 183, 108-109.

Ianchev, I. (2001). Influnce of some geo-chemical ecological factors on some blood haematological characteristics in sheep from Chiprovitei. Zhivotnov, dniNauki, 38(6), 41-43.

Jackson, M.L. (1967). Soil chemical analysis. 1st Ed. Prentice Hall of India Pvt. Ltd. New Delhi.

Koller, A. (1984). Proteins, In Clinical Chemistry: Theory, Analysis and Co-relation, Kaplan L.A., Pesce, A. J. Eds. C.V. Mosby, Toranto, pp. 1268-1327.

Korenovska, M. (2001). Arsenic in cereals, oilseeds and forages produced in Slovakia in 1997-1999. Bulletin-Potravinarskeho-Vyskumu.40 (2), 145-150.

Marsh, W.H. et al., Clin. Chem., (1965), 11, 624.

Pal, A., Nayak, B., Das, B., Hossain, M.A., Ahamed, S. and Chakraborti, D. (2007). Additional danger of arsenic exposure through inhalation from burning of cow dung cakes lacced with arsenic as a fiel in arsenic affected villages in ganga-Meghna-Brahmutra plain. Journal of Environmental Monitoring. 9:1067-1070

Pandey, P. K., Yadav, S., Nair, S. and Bhui, A. (2002). Arsenic contamination of the environment: a new perspective from central-east India. Asstrocl Environ Int. 28 (4),235-245. 
Perkin-Elmer (1979): Analytical Methods Using the MHS-10 Mercury/Hydride System, Perkin-Elmer Corp., Norwalk, CT.

Reitman, S. and Frankel, S. (1957), Am.J.Clin.Path.pp.28, 56.

Rosas, I., Belmont, R., Armienta, A.and Baez, A. (1999). Arsenic concentrations in water, soil,milk and forage in Comarca Lagunera, Mexico. Water, Air and Soil Pollution. Kluwer Academic Publishers.112,133-149.

Rosiles, M.R. (1977). Levels of arsenic detected in cattle at various intervals after accidential poisoning. Veterinaria, Mexico.8(4), 119-122.

Routh, J., Sinha Ray, S. P., Jacks, G., Bhattacharya, A., Datta,S. and Bhattacharya, P. (2003): Safe drinking water -The issue of deep versus shallow wells in two arsenic affected areas in West Bengal,India.7th International Conference on the Biogeochemistry of trace Elements, 2 pp.462-463.

Sahli, B.P.(1982). Arsenic contaminations in cattle liver, kidney and milk.Veterinary and Human toxicology,24(3),173-174.

Sandal, E.E. (1950). Colorimetric determination of traces of metals. Inter science publishers. INC New York.

Sanyal, S.K and Dhillon, K.S. (2005). Arsenic and selenium dynamics in water-soil-plant system: A threat to environmental Quality, Indian Society of Soil Science. ICSWEQ-Proceedings, pp. 239-263.

Sarder, P. (2004). Chronic arsenicosis in chicken and common carp (Cyprenius carpio L.) and its remedial measures through nutritional manipulation. $\mathrm{A} \mathrm{PhD} \mathrm{thesis}$ submitted to West Bengal University of Animal \& Fishery Sciences, West Bengal. 
Sarkar, S. (1989). Studies on anaemia in goats with special reference to minerals and trace elements deficiencies in relation to soil and plant. A $\mathrm{PhD}$ thesis, submitted to B.C.K.V., Mohnanpur, West Bengal.

Schalm, O.W., Jain, N.C. and Corroll, E.J. (1986). Veterinary Haematology, 4th Ed. Lee and Fibiger, Philadelphia.

Selby, L.A., Case, A.A., Dorn, C.R., Wagstaff, D.J.(1974). Public health hazards associated with arsenic poisoning in cattle. Journal of the American Veterinary Medical Association.165(11),1010-1014.

Singh, R.B., Saha, R.C., Mishra, R.K. (2005). Arsenic profile of livestock livestock feeds and livestock products in West Bengal. A report of National Dairy Research Institute.Kalyani, Nadia, West Bengal, India.

Toro, G. and Ackermann, P.G. (1975). Practical Clinical Chemistry. Little Brown \& Co., Boston, pp.154.

USEPA (1973): Water Quality Criteria, Ecological Research Series, Washington, D. C. 